\title{
Influence of early-life risk factors on socioeconomic inequalities in weight gain
}

\section{Isabel Iguacel 1,2,a, Alexandra Chung ${ }^{1,3}$, Emma Gearon ${ }^{1,3}$, Luis A. Moreno ${ }^{2}$, Anna Peeters ${ }^{1}$, Kathryn Backholer ${ }^{1}$}

${ }^{1}$ Deakin University, Geelong, Global Obesity Centre (GLOBE), World Health Organization Collaborating Centre for Obesity Prevention, Centre for Population Health Research School of Health \& Social Development, Burwood, Australia

${ }^{2}$ Growth, Exercise, NUtrition and Development (GENUD) Research Group, Universidad de Zaragoza, Instituto Agroalimentario de Aragón (IA2), Instituto de Investigación Sanitaria de Aragón (IIS Aragón) and Centro de Investigación Biomédica en Red de Fisiopatología de la Nutrición y la Obesidad (CIBEROBN), Zaragoza, Spain

${ }^{3}$ School of Public Health \& Preventive Medicine, Monash University, Melbourne, Australia

Address correspondence to Isabel Iguacel, E-mail: iguacel@unizar.es

${ }^{a}$ Present address: Centre for Population Health Research, The Global Obesity Centre, Deakin University, Locked Bag 20000, Geelong, VIC 3220, Australia

\begin{abstract}
Background Previous research has examined the role of early-life risk factors on childhood weight gain. The extent to which these factors drive socioeconomic differences in weight is unclear. We aimed to quantify the influence of early-life risk factors on the development of socioeconomic inequalities in children's body mass index (BMI) z-score at 10-11 years.

Methods Overall, 2186 children from the Longitudinal Study of Australian Children were examined. Socioeconomic position (SEP) was measured as a continuous composite of parent's education, occupation and income. The Product of Coefficients mediation method was used to quantify the contribution of maternal smoking during pregnancy, gestational diabetes, prematurity, caesarean section, birthweight, not being breastfed, early introduction of solid food, maternal BMI and paternal BMI to the relationship between SEP and BMI z-score.

Results Each increasing decile of SEP (higher SEP) was associated with a 0.05 unit lower ( $95 \% \mathrm{Cl}$ : $-0.06,-0.03$ ) BMI $z$-score at $10-11$ years In total, $83.5 \%$ of these differences in BMI $z$-score could be explained by socioeconomic differences in maternal smoking during pregnancy (26.9\%), maternal BMI (39.6\%) and paternal BMI (17.0\%).

Conclusions Interventions to reduce socioeconomic inequalities in excess weight gain during childhood should support the attainment of a healthy parental weight and prevent smoking during pregnancy.
\end{abstract}

Keywords childhood obesity, maternal obesity, pregnancy, smoking, socioeconomic deprivation

\section{Introduction}

Childhood obesity is a major public health problem. ${ }^{1}$ Consequences of obesity in childhood include increased risk of type 2 diabetes, joint problems and musculoskeletal discomfort, psychological problems and adult obesity, ${ }^{2,3}$ which is associated with a higher incidence of metabolic syndrome, cardiovascular diseases and several cancers. ${ }^{4}$ Despite the stabilization in the prevalence of childhood obesity in some high-income countries ${ }^{5}$ this trend has been commonly limited to children with greater social and economic resources. ${ }^{6}$ Consequently, socioeconomic inequalities in obesity have widened in the last decade.

Pre-, peri- and postnatal risk factors have been identified as determinants of subsequent childhood overweight/obesity. ${ }^{7}$
Early-life risk factors include smoking during pregnancy, parental overweight, gestational diabetes, prematurity, high and low birthweight, caesarean section, not being breastfed and early introduction of solid foods. ${ }^{8}$ These risk factors tend to cluster in socially patterned ways. For example, mothers with a low educational level are more likely to smoke during pregnancy, which increases the risk of preterm birth, and thereby

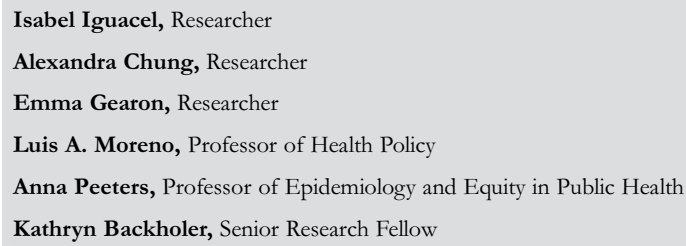


reduces the probability of breastfeeding. ${ }^{9}$ Consequently, children with lower socioeconomic position (SEP) are more likely to accumulate multiple early-life risk factors and to be at a higher risk of excess weight gain during childhood compared to children with higher SEP. Nevertheless, the extent to which these early-life risk factors mediate socioeconomic inequalities in weight gain across childhood is unclear due to limitations in the evidence base.

A systematic review, which identified several modifiable risk factors mediating socioeconomic differences in adiposity among children, stated several limitations to the evidence base: ${ }^{10}$ a lack of research using longitudinal data with advanced mediation methods that quantifies the individual contribution of mediators in the association between SEP and weight gain during childhood and a lack of analyses exploring different age groups throughout childhood using different indicators of SEP. To overcome these limitations, we aimed to use data from the Longitudinal Study of Australian Children and methods for mediation analyses to quantify the influence of early-life risk factors on the development of socioeconomic inequalities in children's body mass index $(\mathrm{BMI})$ z-score at age 10-11 years.

\section{Methods}

\section{Study population}

The LSAC is a nationally representative cross-sequential sample of two cohorts of Australian children recruited in 2004: the birth cohort of (5107 infants aged 0-1 years) and the kindergarten cohort (4983 children aged 4-5 years). The study design and sample information are detailed elsewhere. ${ }^{11}$ A cluster design and stratification of postal codes were used to ensure a geographically representative sample of the Australian population, except for children living in remote areas. Children born between 1999 and 2000 were recruited by the Health Insurance Commission (HIC) from its Medicare Australia enrolment database by mailing out an 'invitation to participate' letter' to the Medicare cardholder.

We included only data from children of the birth cohort as information regarding early-life risk factors was not available for the kindergarten cohort. Overall, 8921 families were contacted to participate in the LSAC study's birth cohort and 5107 agreed to participate. Data collection is ongoing and includes face-to-face interviews conducted by professionals, questionnaires completed by the child's primary caregiver (usually the child's mother) and physical measurements conducted every 2 years from 2004. After 10 years (wave 6), 3764 children remained in the cohort (retention rate $73.7 \%$ ). For this analysis, children with missing values for the exposure, covariates or outcome of interest were excluded. A total of 2186 children were finally included (51.7\% boys; Fig. 1). Participants lost at follow-up and those without complete data were more likely to be of a lower SEP, of Aboriginal or Torres Strait origin, or have a mother who spoke a language other than English as the main language at home (data not shown).

Parental written informed consent was obtained and the protocols for the LSAC study were approved by the Australian Institute of Family Studies Ethics Committee. This analysis was approved by Deakin University Human Research Ethics Committee (2016-161).

\section{Socioeconomic position (exposure)}

A continuous, relative, summary measure of family SEP was generated and validated in the LSAC sample based on each parent's annual income, occupational status and highest level of educational attainment and then dividing this by the number of parents in the home. ${ }^{12}$ Because of the relatively high degree of tracking of SEP across LSAC waves, we used the SEP score that was generated at the first wave of data collection (age 0-1 years). This SEP score was used continuously (in deciles) in our mediation analysis, and categorically (in tertiles) for descriptive statistics.

\section{Anthropometry (outcome)}

Trained professionals measured children's weight in light clothing to the nearest $50 \mathrm{~g}$ by using digital scales and height to the nearest $0.1 \mathrm{~cm}$ by using a portable rigid stadiometer. BMI $\left(\mathrm{kg} / \mathrm{m}^{2}\right)$ was calculated and converted into continuous age and sex-specific BMI z-score based on Centers for Disease Control and Prevention (CDC) growth charts. ${ }^{13}$

\section{Early-life risk factors (mediators)}

Early-life risk factors were divided into prenatal, perinatal and postnatal risk factors (Table 1).

Prenatal outcomes were self-reported by the child's primary caregiver (usually the child's mother) in face-to-face interviews by asking: mother's tobacco use during pregnancy (categorized as yes/no; a mother was considered as a smoker if she smoked during pregnancy, regardless of the number of cigarettes), and gestational diabetes (yes/no).

Perinatal outcomes were collected directly from the child's Health Record Book (i.e. baby book filled in at time of birth): gestational age was categorized into $<37$ weeks (preterm) and $\geq 37$ weeks (term); birthweight, categorized as abnormal weight (including low $<2.5 \mathrm{~kg}$ and high weight 


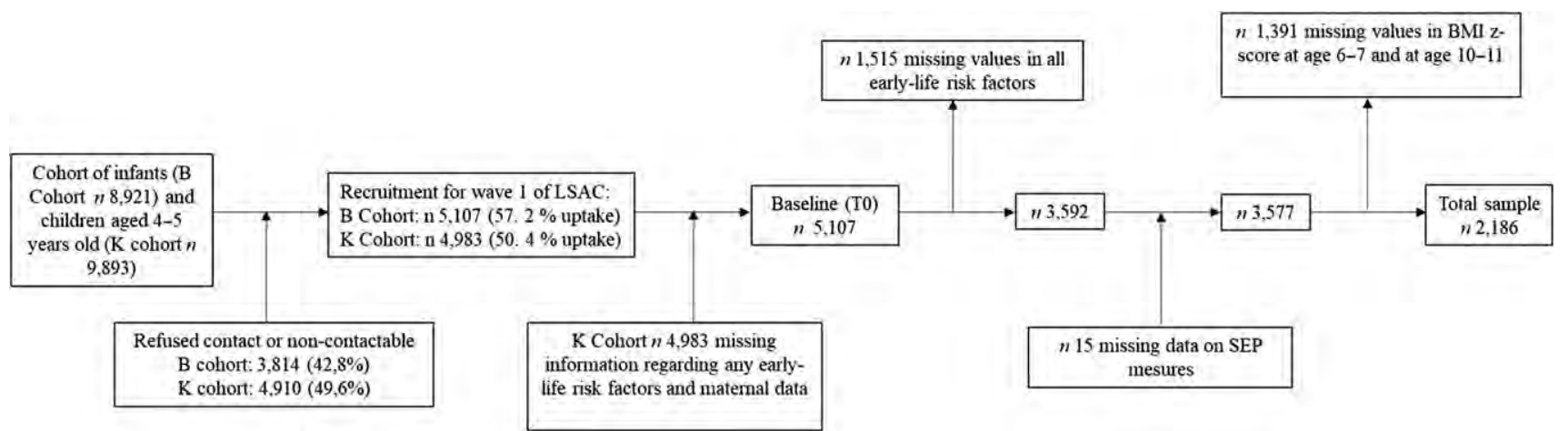

Fig. 1 Selection of the final study sample.

Table 1 Early-life risk factors and hypothesized mechanisms for influencing BMI

\begin{tabular}{|c|c|}
\hline Risk factors & Hypotheses \\
\hline \multicolumn{2}{|l|}{ Prepartum } \\
\hline $\begin{array}{l}\text { Maternal smoking during } \\
\text { pregnancy }\end{array}$ & $\begin{array}{l}\text { Via intrauterine, exposure to smoke results in a prenatal undernutrition. This nutritional deprivation may lead to } \\
\text { increased nutrient achievement later and finally postnatal obesity. }{ }^{25}\end{array}$ \\
\hline Gestational diabetes & $\begin{array}{l}\text { Foetal programming, shared genes and/or shared environments. Maternal gestational hyperglycaemia and } \\
\text { subsequent foetal hyperinsulinemia may predispose offspring to increased adiposity. }{ }^{27}\end{array}$ \\
\hline \multicolumn{2}{|l|}{ Peripartum } \\
\hline Gestational age & $\begin{array}{l}\text { Individuals who were born preterm appear to be more prone to insulin resistance and post-term displayed } \\
\text { accelerated weight velocity and subsequent obesity. }{ }^{28}\end{array}$ \\
\hline Caesarean section & $\begin{array}{l}\text { Caesarean section-born individuals do not make contact at birth with maternal vaginal and intestinal bacteria and } \\
\text { this could lead to long-term changes in the gut microbiota that could increase risk for childhood obesity. }{ }^{29}\end{array}$ \\
\hline Birthweight & $\begin{array}{l}\text { Indicator of conditions experienced in utero. Low and high birthweight are associated with subsequent childhood } \\
\text { obesity through increased leptin levels after catch-up growth during childhood and programming for lean mass, } \\
\text { respectively. }{ }^{30}\end{array}$ \\
\hline \multicolumn{2}{|l|}{ Postpartum } \\
\hline $\begin{array}{l}\text { Exclusive breastfeeding for at } \\
\text { least } 4 \text { months }\end{array}$ & $\begin{array}{l}\text { Breastfeeding may be protective against childhood obesity because it promotes self-regulation of an infant's energy } \\
\text { intake, and the mother may learn to recognize her infant's hunger and satiety cues. }{ }^{31}\end{array}$ \\
\hline Early introduction of solid foods & Formula-fed infants may increase their energy intake when solids are introduced. ${ }^{20}$ \\
\hline $\begin{array}{l}\text { Maternal and paternal } \\
\text { overweight/obesity }\end{array}$ & $\begin{array}{l}\text { Parental overweight and obesity could influence the risk of obesity in their descendants due to shared genes and } \\
\text { environmental factors within families. }{ }^{32}\end{array}$ \\
\hline
\end{tabular}

$\geq 4 \mathrm{~kg}$ ) and normal weight $(2.5$ to $<4 \mathrm{~kg})$ and caesarean section (yes/no). The decision to dichotomize birthweight was a requirement of using the binary_mediation command in Stata requiring mediators to be coded as linear or dichotomous variables. This categorization of birthweight has its limitation as the mechanism of influence on childhood weight gain is likely to differ for low, normal and high birthweights. However, we found no significant relationship between SEP and birthweight, regardless of the definition used, thereby precluding it as a possible mediator of the relationship between SEP and 10-year z-BMI in our study (see Sensitivity analyses). For descriptive purposes, birthweight was defined as low, normal and high birthweight in Table 1.
Postnatal outcomes 'breastfeeding for at least 4 months and early introduction of solid foods' were obtained from mothers with the following respective questions 'How old was your child when he/she completely stopped being breastfed?' (categorized for our analyses as breastfed for at least 4 months, yes/no) and 'How old was your child (in days) when he/she had solid food regularly?' (categorized as early introduction of solid food (yes/no) when the mother answered before 120 days). This last question was accompanied by the explanatory text 'Regularly $=$ more than twice a week for several continuous weeks. Solid food = baby cereals, pureed fruits, etc. not milks or drinks'. We chose to dichotomize breastfeeding at 4 months because evidence 
suggests that being exclusively breastfed for at least 4 months reduces the risk of overweight/obesity later in life. ${ }^{14,15}$

Parents indicated their weight and height at time of the interview, when infants were aged between 26 and 79 weeks, from which we calculated maternal BMI and paternal BMI (used continuously in our analyses).

\section{Covariates}

We included the following covariates at wave 1: mother's age, child's age and sex, aboriginal or Torres Strait Islander (ATSI) origin determined from parents' response to the question 'Is Child of Aboriginal or Torres Strait Islander origin? (yes/no) and mother's main language other than English (LOTE) determined by the question 'Does Mother speak a language other than English at home?'.

\section{Descriptive analysis}

For continuous covariates, mean and standard deviation (SD) were reported.

\section{Longitudinal mediation analyses}

We conducted multiple mediation analyses using MacKinnon's product of coefficients methods ${ }^{16}$ to test the hypothesis that early-life risk factors mediate the relationship between SEP in the first year of life (wave 1) and BMI z-score at age 10-11 years (wave 6) (Fig. S1). All models were adjusted for wave 1 covariates including child's age, sex, mother's age, ATSI origin and LOTE as mother's main language at home. For dichotomous variables the reference category was considered the normal (healthy) value. We performed the following steps for our mediation analyses: (i) a linear regression model was fitted to determine the total relationship between SEP (wave 1) and BMI $z$-score (wave 6 ) adjusted for all confounders ( $c$ coefficient); (ii) separate logistic regression models were fitted to determine the independent relationship between SEP and each mediator at wave 1 (except when the outcome was a continuous measure of maternal and paternal BMI in which linear regression models were fitted) adjusted for all confounders ( $a$ coefficient); (iii) a single linear regression model was fitted to determine the relationship between each mediator (wave 1) and BMI z-score (wave 6) adjusted for all confounders, the exposure (SEP), and all other mediating variables ( $b$ coefficient); (iv) the binary_mediation command in Stata was used to generate standardized coefficients from all models in steps $1-3$ to account for the differing logit and linear scales and provided the indirect effect of SEP (wave 1) on BMI z-score (wave 6) through each of the individual mediating variables (wave 1) by taking the product of the standardized $a$ - and $b$-coefficients. The sum of all indirect effects (sum of $a b$ for all significant individual mediators) yielded the total indirect effect through all mediators. We used a bootstrap with 5000 replications to obtain the standardized $c$ - and $a b$-coefficients and their respective 95\% confidence intervals (CI); (v) The proportion mediated (for each individual mediator and for all significant mediators combined) was determined by dividing the indirect effect (standardized $a b$ coefficient) by the total effect (standardized $c$ coefficient). All assumptions related to regression and MacKinnon mediation methods were tested and upheld. ${ }^{16}$

\section{Sensitivity analyses}

We tested if our mediation results were robust by (i) selecting an earlier age group as our outcome (BMI z-score at age 6-7 years); (ii) dichotomizing our outcome to non-overweight (thin and normal weight) versus overweight (overweight and obese) according to the International Obesity Taskforce ageand gender-specific criteria thresholds ${ }^{17}$ and (iii) using mother's highest level of educational attainment as an alternative measure of SEP, categorized as low education (high school or less), medium (graduate certificate, diploma or advanced diploma) and high (bachelor or postgraduate qualification).

We calculated the impact of including the mediator, birthweight, as dichotomous (normal or abnormal birthweight) by testing the ' $a$ ' and ' $b$ ' relationship with birthweight coded as a three categorical variable (low, medium and high birthweight).

We determined whether our analyses were sensitive to nonresponse and attrition by applying LSAC sample weights ${ }^{11}$ to our descriptive analyses and regression models. As we could not incorporate sample weights into the stata binary_mediation command, we tested the impact of including these LSAC sample weights on all ' $a$ ' and ' $b$ ' relationships.

All analyses were performed using Stata 14.0 version.

\section{Results}

Table 2 summarizes crude sociodemographic and anthropometric characteristics of children and prenatal, perinatal and postnatal factors according to tertiles of SEP. The proportion of overweight and obesity was higher among children with a lower SEP compared to children with a higher SEP. A higher percentage of several early-life risk factors (maternal smoking during pregnancy, not being breastfed, early introduction of solid food and maternal overweight/obesity) was observed among children with a lower SEP compared to children with a higher SEP. 
Table 2 Population characteristics according to tertile of socioeconomic position

\begin{tabular}{|c|c|c|c|}
\hline & $\begin{array}{c}\text { Lower } \\
\text { SEP }\end{array}$ & $\begin{array}{l}\text { Middle } \\
\text { SEP }\end{array}$ & $\begin{array}{c}\text { Higher } \\
\text { SEP }\end{array}$ \\
\hline$n=2186$ & $424(19.4 \%)$ & $775(35.4 \%)$ & $987(45.1 \%)$ \\
\hline \multicolumn{4}{|l|}{ Baseline (wave 1) } \\
\hline Sex (\% male) & $48.8 \%$ & $50.4 \%$ & $53.6 \%$ \\
\hline Age (months) & $8.8(2.3)$ & $8.6(2.3)$ & $9.4(2.2)$ \\
\hline Mother's age & $30.3(5.4)$ & $31.5(4.7)$ & $33.1(4.0)$ \\
\hline Aboriginal or Torres Strait Islander & $3.5 \%$ & $1.8 \%$ & $0.6 \%$ \\
\hline LOTE as mother's main language spoken at home & $9.4 \%$ & $8.1 \%$ & $11.3 \%$ \\
\hline \multicolumn{4}{|l|}{ Prenatal factors } \\
\hline \multicolumn{4}{|l|}{ Maternal smoking during pregnancy } \\
\hline No & $77.8 \%$ & $86.1 \%$ & $94.9 \%$ \\
\hline Yes & $22.2 \%$ & $13.9 \%$ & $5.1 \%$ \\
\hline \multicolumn{4}{|l|}{ Gestational diabetes } \\
\hline No & $93.4 \%$ & $95.7 \%$ & $94.8 \%$ \\
\hline Yes & $6.6 \%$ & $4.3 \%$ & $5.2 \%$ \\
\hline \multicolumn{4}{|l|}{ Perinatal factors } \\
\hline \multicolumn{4}{|l|}{ Gestational age } \\
\hline Term & $93.9 \%$ & $92.5 \%$ & $94.9 \%$ \\
\hline Preterm & $6.1 \%$ & $7.5 \%$ & $5.1 \%$ \\
\hline \multicolumn{4}{|l|}{ Caesarean section } \\
\hline No & $74.1 \%$ & $68.8 \%$ & $67.2 \%$ \\
\hline Yes & $27.8 \%$ & $31.2 \%$ & $32.8 \%$ \\
\hline \multicolumn{4}{|l|}{ Birthweight } \\
\hline Normal & $78.1 \%$ & $81.0 \%$ & $82.6 \%$ \\
\hline Low & $5.4 \%$ & $5.9 \%$ & $3.8 \%$ \\
\hline High & $16.5 \%$ & $13.1 \%$ & $13.6 \%$ \\
\hline \multicolumn{4}{|l|}{ Postnatal factors } \\
\hline \multicolumn{4}{|l|}{ Maternal overweight } \\
\hline No & $46.0 \%$ & $54.0 \%$ & $65.0 \%$ \\
\hline Yes & $54.0 \%$ & $46.0 \%$ & $35.0 \%$ \\
\hline \multicolumn{4}{|l|}{ Paternal overweight } \\
\hline No & $33.0 \%$ & $31.1 \%$ & $33.8 \%$ \\
\hline Yes & $67.0 \%$ & $69.9 \%$ & $66.2 \%$ \\
\hline \multicolumn{4}{|l|}{ Breastfeeding at least 4 months } \\
\hline Yes & $48.1 \%$ & $60.5 \%$ & $69.6 \%$ \\
\hline No & $51.9 \%$ & $39.5 \%$ & $30.4 \%$ \\
\hline \multicolumn{4}{|l|}{ Introduction of solid foods before 4 months } \\
\hline No & $85.9 \%$ & $92.3 \%$ & $94.3 \%$ \\
\hline Yes & $14.4 \%$ & $7.7 \%$ & $5.7 \%$ \\
\hline \multicolumn{4}{|l|}{ Wave 4 (age 6-7 years) } \\
\hline BMI z-score & $0.50(0.99)$ & $0.36(0.95)$ & $0.30(0.89)$ \\
\hline Overweight/obese & $22.4 \%$ & $16.9 \%$ & $14.9 \%$ \\
\hline \multicolumn{4}{|l|}{ Wave 6 (age $10-11$ years) } \\
\hline BMI z-score & $0.47(1.06)$ & $0.32(1.04)$ & $0.15(0.95)$ \\
\hline Overweight/obese & $32.3 \%$ & $25.7 \%$ & $16.6 \%$ \\
\hline
\end{tabular}

Figures in table are means and standard deviations or proportions. SEP, socioeconomic position; LOTE, language other than English; BMI, body mass index. 
Table 3 Results from mediation analysis examining the contribution of early-life risk factors on the development of socioeconomic differences in BMI z-score at age 10

\begin{tabular}{|c|c|c|c|c|c|c|c|}
\hline & \multicolumn{2}{|c|}{$\begin{array}{l}\text { Association between SEP } \\
\text { and mediator }\end{array}$} & \multicolumn{2}{|c|}{$\begin{array}{l}\text { Association between } \\
\text { mediator and BMI } \\
\text { z-score }\end{array}$} & \multicolumn{2}{|c|}{ Mediated effect } & \multirow[t]{2}{*}{$\begin{array}{l}\text { Proportion mediated } \\
\%\end{array}$} \\
\hline & $a^{*}$ & $95 \% \mathrm{Cl}$ & $b^{*}$ & $95 \% \mathrm{Cl}$ & $a b^{*}$ & $95 \% \mathrm{Cl}$ & \\
\hline Maternal smoking during pregnancy & -0.26 & $(-0.31,-0.20)$ & 0.32 & $(0.19,0.45)$ & -0.035 & $(-0.051,-0.021)$ & $26.9 \%$ \\
\hline Gestational diabetes & -0.05 & $(-0.12,0.03)$ & -0.05 & $(-0.23,0.13)$ & 0.001 & $(-0.003,0.005)$ & \\
\hline Preterm & -0.04 & $(-0.11,0.03)$ & -0.12 & $(-0.29,0.04)$ & 0.001 & $(-0.001,0.006)$ & \\
\hline Caesarean section & 0.02 & $(-0.02,0.05)$ & 0.07 & $(-0.02,0.15)$ & 0.001 & $(-0.001,0.003)$ & \\
\hline Abnormal birthweight & -0.02 & $(-0.07,0.02)$ & 0.09 & $(-0.01,0.19)$ & -0.001 & $(-0.003,0.001)$ & \\
\hline Non-breastfed at least 4 months & -0.14 & $(-0.18,-0.11)$ & -0.03 & $(-0.11,0.06)$ & 0.003 & $(-0.009,0.012)$ & \\
\hline Maternal BMI & -0.38 & $(-0.47,-0.29)$ & 0.05 & $(0.04,0.06)$ & -0.051 & $(-0.066,-0.038)$ & $39.6 \%$ \\
\hline Paternal BMI & -0.18 & $(-0.24,-0.11)$ & 0.05 & $(0.04,0.06)$ & -0.022 & $(-0.032,-0.016)$ & $17.0 \%$ \\
\hline Early introduction of solid foods & -0.16 & $(-0.22,-0.10)$ & -0.05 & $(-0.20,0.10)$ & 0.003 & $(-0.005,0.012)$ & \\
\hline Sum of significant mediators & & & & & -0.108 & $(-0.132,-0.008)$ & $83.5 \%$ \\
\hline
\end{tabular}

Bold type denotes significant values. *a, coefficient adjusted for all confounders (child's age, sex, mother's age, ATSI origin and LOTE as mother's main language at home); $b$, coefficient adjusted for all confounders, the exposure (SEP), and all other mediating variables; ab, standardized $a b$ coefficient.

\section{Mediation results}

Results of mediation analysis can be found in Table 3.

\section{Associations between SEP and children's BMI z-score at age 10-11 years (c coefficient)}

Each increasing decile of SEP (higher SEP) was associated with a 0.05 unit lower (95\% C:I -0.06, -0.03) BMI z-score at age $10-11$ years.

\section{Relationship between SEP and each mediator (a coefficient)}

We observed significant negative associations between SEP and maternal smoking $(-0.26,95 \% \mathrm{CI}$ : $-0.32,-0.20)$, nonbreastfed for at least 4 months $(-0.14,95 \%$ CI: $0.11,0.18)$, maternal BMI (-0.38, 95\% CI: $-0.47,-0.29)$, paternal BMI $(-0.18,95 \%$ CI: $-0.24,-0.11)$ and early introduction of solid foods $(-0.16,95 \% \mathrm{CI}:-0.22,-0.10)$. No association was observed between SEP and preterm birth, caesarean section and abnormal birthweight.

\section{Relationship between each mediator and BMI $z$-score at age $\mathbf{1 0}-\mathbf{1 1}$ years ( $b$ coefficient)}

We observed significant positive associations between maternal smoking during pregnancy and child's BMI z-score (0.32, 95\% CI: 0.19, 0.45), between maternal BMI and child's BMI z-score (0.05, 95\% CI: 0.04, 0.06) and between paternal BMI and child's BMI z-score (0.05, 95\% CI: 0.04, 0.06). No associations were observed between any other early-life risk factors studied and BMI z-score.
The mediating effect of early-life risk factors on the relationship between SEP and BMI $z$-score at age 10-11 years (ab coefficient)

Of the early-life risk factors examined, maternal smoking during pregnancy, maternal BMI and paternal BMI were significantly associated with both the exposure (SEP; a-coefficient) and the outcome (BMI z-score at age 10-11 years; b-coefficient). Maternal smoking during pregnancy, maternal BMI and paternal BMI mediated 26.9, 39.6 and $17.0 \%$ of the relationship between SEP and children's BMI z-score, respectively. These three early-life risk factors explained $83.5 \%$ of the socioeconomic differential in BMI z-score at age 10-11 years $(-0.11,95 \% \mathrm{CI}:-0.13,-0.01)$.

\section{Sensitivity analyses}

When using BMI z-score at age 6-7 years as our outcome (instead of at age 10-11 years) although the total mediated effect of early-life risk factors was similar to our primary analyses, only maternal and paternal BMI were significant mediators, which mediated 60.3 and $23.2 \%$ of the relationship between SEP and BMI z-score, respectively (Table S1). When using mother's education as our exposure the same mediators were significantly related to SEP and to BMI z-score at age 10 years as was observed in the primary analysis (Table S2). When dichotomizing our outcome variable to represent normal weight and overweight or obese the same mediators were identified as the primary analyses, albeit to a lesser degree $(17.2 \%$ for maternal smoking during 
pregnancy, $26.4 \%$ for maternal BMI and $10.3 \%$ for paternal BMI) (Table S3).

The relationships between SEP and all mediators and between all mediators and BMI z-score did not appreciably differ after applying LSAC sample weights (Table S4).

\section{Discussion}

\section{Main finding of this study}

Using a longitudinal cohort of Australian children, we demonstrate that early-life risk factors can explain more than $80 \%$ of the differences in children's BMI $\approx$-score at age 10 across SEP groups. Maternal smoking during pregnancy, maternal BMI and paternal BMI (collected when children were aged 0-1 years) explained $26.9,39.6$ and $17.0 \%$ of the socioeconomic differences in children's BMI $z$-score, respectively.

Our results are consistent with previous research. Using a cohort of children born in the UK, Massion et al. ${ }^{18}$ identified that maternal smoking during pregnancy and maternal prepregnancy overweight were the most important determinants of inequalities in childhood overweight at 11 years (mediating $\sim 40 \%$ of inequalities in childhood overweight). Our findings also corroborate results from a Dutch cohort of 6-year-old children, where paternal BMI and smoking during pregnancy attenuated $54 \%$ of the association between maternal education and BMI SD scores. ${ }^{19}$

In our analysis being breastfed for at least 4 months was not associated with a lower BMI at age 10-11 years and therefore was not considered a significant mediator of the association between SEP and children's BMI z-score. Breastfeeding has been recognized as a mediator of SEP differences in children's adiposity ${ }^{20}$ and mainly in children in the first year of life. ${ }^{21}$ Nevertheless, the evidence in the literature for this relationship is inconsistent with some studies reporting breastfed children have a lower risk of childhood obesity than those who have not been breastfed ${ }^{22}$ while others stated that this evidence could be influenced by confounding factors and breastfeeding would not be likely to be a protective factor for childhood obesity. ${ }^{23}$

We also found an inverse relationship between SEP and maternal smoking, early introduction of solid food, not being breastfed for at least 4 months and parental BMI, which has been corroborated in previous investigations. ${ }^{24}$ Possible mechanisms of maternal smoking and parental BMI on inequalities in BMI are likely to be explained through their action on weight gain. Maternal smoking is associated with foetal growth retardation and subsequent catch-up growth, affectation of the hypothalamic function exerting a negative impact on appetite control or by enhancing dietary preference for fat through neural pathways. ${ }^{25}$ Parental BMI may influence the risk of offspring obesity via genes that promote, or are less resistant, to weight gain and environmental and behavioural factors within families that drive energy imbalance. ${ }^{26}$

\section{What is already known on this topic}

In high-income countries, children with a lower SEP are more likely to be overweight or obese compared to children with a higher SEP. Early-life risk factors, such as maternal smoking, not being breastfeed, early introduction of solid food or maternal overweight and obesity, are socially patterned and have been identified as predictors of childhood obesity.

\section{What this study adds}

Whilst there have been a small number of studies that have investigated the contribution of individual early-life risk factors to socioeconomic inequalities in adiposity among children, ${ }^{10}$ to our knowledge, this is the first paper to perform multiple mediation analyses using MacKinnon's product of coefficients methods at two time points (from birth to age 6-7 and from birth to age 10-11 years) in an Australian sample. We used two indicators of SEP (mother's education and a composite indictor) and two methods of assessing children's outcome (BMI z-score and a dichotomous measure of normal or overweight) to provide a more precise role of the explored mediators. We demonstrated that early-life risk factors can explain more than $80 \%$ of the socioeconomic differences in excess weight among children at age 10-11 years. Maternal BMI was the largest contributor to the socioeconomic inequalities in children's weight at age 10-11 years, followed by maternal smoking during pregnancy and paternal BMI. Interventions that lead to reduction in maternal smoking during pregnancy and in parental BMI across the socioeconomic gradient are essential to reduce socioeconomic inequalities in childhood overweight and obesity.

\section{Limitations of this study}

The limitations of this study include possible selection bias because some participants (mainly children whose parents had a lower SEP, of Indigenous origin, or spoke a language other than English as the main language at home) did not respond to all study questions or did not continue to participate across study waves and the reliance on self-reported measures.

\section{Acknowledgements}

This article uses data from Growing Up in Australia: The Longitudinal Study of Australian Children (LSAC). The study is conducted in partnership between the Department 
of Social Services (DSS), the Australian Institute of Family Studies (AIFS) and the Australian Bureau of Statistics (ABS). The findings and views reported in this paper are those of the authors and should not be attributed to DSS, AIFS or the ABS.

\section{Supplementary data}

Supplementary data are available at the Journal of Public Health online.

\section{Funding}

I.I. has been financed by the Formación de Profesorado Universitario (FPU) (grant reference FPU014/00922) Predoctoral Programs (Spanish Ministry of Education and Science). A.C. is the recipient of a Monash University Research Training Program Scholarship. A.P. is a researcher within a National Health and Medical Research Council, Centre for Research Excellence in Obesity Policy and Food Systems grant (APP1041020). A.P. is recipient of an National Health and Medical Research Council Career Development Fellowship.

\section{Conflict of interest}

The authors declare that there is no conflict of interest.

\section{References}

1 World Health Organization (WHO). Global Strategy on Diet, Physical Activity and Health: Childhood Obesity and Overweight. http://www.who.int/ dietphysicalactivity/childhood/en/. (29 June 2017, date last accessed)

2 Gordon-Larsen P, The NS, Adair LS. Longitudinal trends in obesity in the US from adolescence to the third decade of life. Obesity (Silver Spring) 2010;18(9):1801-4.

3 de Sa Pinto AL, de Barros Holanda PM, Radu AS et al. Musculoskeletal findings in obese children. J Paediatr Child Health 2006;42(6):341-4.

4 Biro FM, Wien M. Childhood obesity and adult morbidities1234. Am J Clin Nutr 2010;91:1499S-505S.

5 Rokholm B, Baker JL, Sorensen TI. The levelling off of the obesity epidemic since the year 1999-a review of evidence and perspectives. Obes Rev 2010;11(12):835-46.

6 White J, Rehkopf D, Mortensen LH. Trends in socioeconomic inequalities in body mass index, underweight and obesity among english children, 2007-2008 to 2011-2012. PLoS One 2016;11(1): e0147614.

7 Reilly JJ, Armstrong J, Dorosty AR et al. Early life risk factors for obesity in childhood: cohort study. Br Med J 2005;330(7504):1357.

8 Bammann K, Peplies J, De Henauw S et al. Early life course risk factors for childhood obesity: the IDEFICS case-control study. PLoS One 2014;9(2):e86914.
9 Oves Suarez B, Escartin Madurga L, Samper Villagrasa MP et al. [Immigration and factors associated with breastfeeding. CALINA study]. An Pediatr (Barc) 2014;8(1):32-8.

10 Gebremariam MK, Lien N, Nianogo RA et al. Mediators of socioeconomic differences in adiposity among youth: a systematic review. Obes Rev 2017;18(8):880-98.

11 Soloff C, Johnstone R, Lawrence D. LSAC Sample Design (Technical Paper Number 1). Melbourne: Australian Institute of Family Studies, 2005.

12 Blakemore T, Strazdins L, Gibbings J. Measuring family socioeconomic position. Aust Soc Policy 2009;8:121-68.

13 Kuczmarski RJ, Ogden CL, Grummer-Strawn LM et al. CDC growth charts: United States. Adv Data 2000;314:1-27.

14 Grube MM, von der Lippe E, Schlaud M et al. Does breastfeeding help to reduce the risk of childhood overweight and obesity? A propensity score analysis of data from the KiGGS study. PLoS One 2015;10(3):e0122534.

15 Kreichauf S, Pfluger M, Hummel S et al. [Effect of breastfeeding on the risk of becoming overweight in offspring of mothers with type 1 diabetes]. Dtsch Med Wochenschr 2008;133(22):1173-7.

16 MacKinnon DP, Fairchild AJ, Fritz MS. Mediation analysis. Annu Rev Psychol 2007;58:593-614.

17 Cole TJ, Bellizzi MC, Flegal KM et al. Establishing a standard definition for child overweight and obesity worldwide: international survey. Br Med J 2000;320(7244):1240-3.

18 Massion S, Wickham S, Pearce A et al. Exploring the impact of early life factors on inequalities in risk of overweight in UK children: findings from the UK Millennium Cohort Study. Arch Dis Child 2016;101(8):724-30.

19 Bouthoorn SH, Wijtzes AI, Jaddoe VW et al. Development of socioeconomic inequalities in obesity among Dutch pre-school and school-aged children. Obesity (Silver Spring) 2014;22(10): $2230-7$.

20 Gibbs BG, Forste R. Socioeconomic status, infant feeding practices and early childhood obesity. Pediatr Obes 2014;9(2): $135-46$.

21 Wijlaars LP, Johnson L, van Jaarsveld CH et al. Socioeconomic status and weight gain in early infancy. Int J Obes (Lond) 2011;35(7): $963-70$.

22 Yan J, Liu L, Zhu Y et al. The association between breastfeeding and childhood obesity: a meta-analysis. BMC Public Health 2014;14 (1):1267.

23 Lefebvre CM, John RM. The effect of breastfeeding on childhood overweight and obesity: a systematic review of the literature. $J A m$ Assoc Nurse Pract 2014;26(7):386-401.

24 Dubois L, Girard M. Early determinants of overweight at 4.5 years in a population-based longitudinal study. Int J Obes 2006;30(4): 610-7.

25 Oken E, Levitan EB, Gillman MW. Maternal smoking during pregnancy and child overweight: systematic review and meta-analysis. Int J Obes (Lond) 2008;32(2):201-10.

26 Whitaker RC, Wright JA, Pepe MS et al. Predicting obesity in young adulthood from childhood and parental obesity. N Engl J Med 1997; 337(13):869-73. 
27 Kim SY, Sharma AJ, Callaghan WM. Gestational diabetes and childhood obesity: what is the link? Curr Opin Obstet Gynecol 2012;24(6): 376-81.

28 Thomas EL, Saud NBA, Durighel G et al. The effect of preterm birth on adiposity and metabolic pathways and the implications for later. Life Clin Lipidol 2012;7(3):275-88.

29 Kuhle S, Tong OS, Woolcott CG. Association between caesarean section and childhood obesity: a systematic review and metaanalysis. Obes Rev 2015;16(4):295-303.
$30 \mathrm{Yu} \mathrm{ZB}$, Han SP, Zhu GZ et al. Birth weight and subsequent risk of obesity: a systematic review and meta-analysis. Obes Rev 2011;12(7): $525-42$.

31 Arenz S, Ruckerl R, Koletzko B et al. Breast-feeding and childhood obesity—a systematic review. Int J Obes Relat Metab Disord 2004;28 (10):1247-56.

$32 \mathrm{Yu}$ Z, Han S, Zhu J et al. Pre-pregnancy body mass index in relation to infant birth weight and offspring overweight/obesity: a systematic review and meta-analysis. PLoS One 2013;8(4):e61627. 